\title{
The Genetic Association Between ADHD Symptoms and Reading Difficulties: The Role of Inattentiveness and IQ
}

\author{
Yannis Paloyelis • Fruhling Rijsdijk • Alexis C. Wood • \\ Philip Asherson • Jonna Kuntsi
}

Published online: 17 June 2010

(C) The Author(s) 2010. This article is published with open access at Springerlink.com

\begin{abstract}
Previous studies have documented the primarily genetic aetiology for the stronger phenotypic covariance between reading disability and ADHD inattention symptoms, compared to hyperactivity-impulsivity symptoms. In this study, we examined to what extent this covariation could be attributed to "generalist genes" shared with general cognitive ability or to "specialist" genes which may specifically underlie processes linking inattention symptoms and reading difficulties. We used multivariate structural equation modeling on IQ, parent and teacher ADHD ratings and parent ratings on reading difficulties from a general population sample of 1312 twins aged 7.910.9 years. The covariance between reading difficulties and ADHD inattention symptoms was largely driven by genetic (45\%) and child-specific environment (21\%) factors not shared with IQ and hyperactivity-impulsivity; only $11 \%$ of the covariance was due to genetic effects common with IQ. Aetiological influences shared among all phenotypes explained $47 \%$ of the variance in reading difficulties. The current study, using a general population sample, extends previous findings by showing, first, that the shared genetic variability between reading difficulties and ADHD inattention symptoms is largely independent from genes contributing to general cognitive ability and, second, that child-specific environment factors, independent from IQ, also contribute
\end{abstract}

\footnotetext{
Y. Paloyelis $(\triangle) \cdot$ F. Rijsdijk $\cdot$ A. C. Wood $\cdot$ P. Asherson $\cdot$

J. Kuntsi

MRC Social, Genetic and Developmental Psychiatry Centre, Institute of Psychiatry,

King's College London, UK

e-mail: yannis.paloyelis@kcl.ac.uk

A. C. Wood

Department of Epidemiology and Section on Statistical Genetics, University of Birmingham at Alabama,

Birmingham, USA
}

to the covariation between reading difficulties and inattention symptoms.

Keywords ADHD - Reading disability - Inattention · Comorbidity $\cdot$ Twins $\cdot$ IQ

\section{Introduction}

The co-occurrence between attention deficit-hyperactivity disorder (ADHD), which is characterized by developmentally inappropriate levels of inattentive and/or hyperactiveimpulsive behaviours (American Psychiatric Association (APA) 2000), and reading disability, whether defined as diagnostic categories or quantitative traits, is well documented (August and Garfinkel 1990; Dykman and Ackerman 1991; Trzesniewski et al. 2006; Willcutt and Pennington 2000a,b). It reflects a strong phenotypic association between reading disability and ADHD inattention symptoms, which has been largely attributed to shared genes (Martin et al. 2006; Willcutt and Pennington 2000a; Willcutt et al. 2000, 2007b). The present study, using a genetically informative design, extends this research by investigating to what extent the common genetic variability between reading difficulties and ADHD inattention symptoms is also shared with general cognitive ability, as measured by IQ.

Previous twin studies have shown that both reading ability/disability (Alarcon and DeFries 1997; Byrne et al. 2008; Gayan and Olson 2003; Harlaar et al. 2005a; Tiu et al. 2003; Wadsworth et al. 2000) and ADHD symptoms (Kuntsi et al. 2004; Wood et al. 2009) share genetic variability with IQ. Therefore, it is possible that any shared genetic variability between inattention symptoms and reading disability could reflect a common genetic associa- 
tion shared with general intelligence. This idea was supported by evidence that genetic and environmental influences shared with IQ accounted for the covariance between reading performance and a cognitive attention measure (Zumberge et al. 2007). However, it is not possible to generalize directly from cognitive attention processes to behavioural inattention problems (Marzocchi et al. 2009; Warner-Rogers et al. 2000). Similar manifestations of inattention problems may reflect diverse cognitive deficits, and the relationship between overt behavioural inattention and deficits in cognitive attention is neither simple nor direct (Marzocchi et al. 2009; Warner-Rogers et al. 2000).

Indeed, behavioural and genetic evidence at the overt symptom level suggests that shared aetiological influences between inattention symptoms and reading disability are likely to be independent of IQ. A recent study reported similar estimates of common genetic influences between a brief measure of hyperactive/inattentive behaviours and a composite measure of academic achievement (including reading) before and after adjusting the latter for IQ (Saudino and Plomin 2007). Other studies have shown that early inattention symptoms predicted later reading achievement even after controlling for prior reading ability and IQ (Rabiner and Coie 2000; Rabiner and Malone 2004).

There is a need to understand better the aetiology of the covariance between ADHD inattention symptoms and reading disability because, to be effective at improving reading performance in the context of inattention problems, intervention programs need to address the specific deficits giving rise to the covariance between these disorders (Rabiner and Malone 2004). If the covariance could be attributed to shared aetiological influences that are independent of IQ, this would indicate the presence of specific neurocognitive deficits contributing to these disorders that were independent of possible "generalist" mechanisms spanning cognitive processes and learning abilities/disabilities across domains (Haworth et al. 2009).

Bivariate studies allow the parsing of the covariance between two phenotypes into distinct genetic and environmental components. The genetic and environmental correlations provide estimates of the degree to which the covariance between two phenotypes reflects shared genes or environmental factors, respectively. The inclusion of additional variables of interest in the multivariate case makes possible the estimation of the extent to which the genetic (or environmental) overlap is further shared with the additional variables (such as IQ). Multivariate designs offer improved power by decreasing the rate of false positive type I error rate (by decreasing the number of tests) and by taking into account the covariance among traits for each individual (Hottenga and Boomsma 2008).

Existing studies have employed bivariate designs, examining the aetiology between reading deficits and a single ADHD subtype, or ADHD symptom dimension, at a time, excluding IQ (Martin et al. 2006; Willcutt et al. 2000, 2007b). In the present study we replicate and extend previous research by using a general population sample and employing a multivariate design, including measures of IQ and both ADHD inattention and hyperactivityimpulsivity symptoms. The use of an unselected, general population sample avoids possible selection biases associated with clinic-referred or selected community samples and allows the generalization of findings to the general population. Inattention, hyperactivity-impulsivity and reading disability are all considered to be the tails of normally distributed traits, reflecting the normal distribution of genetic risk in the population (Chen et al. 2008; Harlaar et al. 2005b; Levy et al. 1997; Shaywitz et al. 1992). Studying general population samples is useful in understanding the extremes, as quantitative genetic and epidemiological evidence supports the validity of making inferences from population data to clinical cases in ADHD (Chen et al. 2008).

Specifically, our study aimed to: (1) Confirm the substantially larger phenotypic and genetic correlations between reading difficulties and ADHD inattention symptoms, compared to hyperactivity-impulsivity symptoms. (2) Investigate, for the first time, to what extent the common genetic variability between ADHD inattention symptoms and reading difficulties is also shared with IQ and hyperactivity-impulsivity symptoms. (3) Assess how much of the variance in reading difficulties could be attributed to aetiological influences shared with the ADHD symptom domains and IQ, thus providing an estimate of their relative importance in understanding the aetiology of reading difficulties. (4) Finally, examine the possibility of gender differences in the aetiology for the covariation between reading difficulties and inattention symptoms.

\section{Method}

Sample and Procedure

Participants are members of the Study of Activity and Impulsivity Levels in children (SAIL), a general population sample of twins aged 7.9-10.9 years. They were recruited from the Twins' Early Development Study (TEDS; Trouton et al. 2002), a birth cohort study which had invited parents of all twins born in England and Wales during 1994-1996 to enrol. Despite attrition, the TEDS families continue to be reasonably representative of the UK population with respect to parental occupation, education and ethnicity (Oliver and Plomin 2006). Zygosity has been determined using a standard zygosity questionnaire which has shown $95 \%$ accuracy (Price et al. 2000). 
TEDS families were invited to take part if they fulfilled the following SAIL project inclusion criteria: twins' birthdates between September 1, 1995 and December 31, 1996; lived within a feasible travelling distance from the research centre; White European ethnic origin (to reduce population heterogeneity for molecular genetic studies); recent participation in TEDS, as indicated by return of questionnaires at either 4- or 7-year data collection point; no extreme pregnancy, perinatal difficulties, specific medical syndromes, chromosomal anomalies or epilepsy; not participating in other current TEDS substudies; and not on stimulant or other neuropsychiatric medications.

Of the 1,230 suitable families contacted, 672 families $(55 \%)$ agreed to participate. Overall, the sample is as representative of the general population as is feasible for a study of this kind, and previous analyses on TEDS indicated that attrition was not due to ADHD symptoms. For example, Saudino et al. (2005) found that twins who participated at age 7 assessments were not significantly different in parent ratings of hyperactivity from lost twins at age $2(t=1.77 ; p=0.08)$. However slight bias towards higher parental occupational classification, compared to the original TEDS sample, should be noted $39 \%$ of mothers and $52 \%$ of fathers in managerial or professional jobs, compared to $28 \%$ and $40 \%$, respectively). Thirty-two children were subsequently excluded due to: IQ $<70$, epilepsy, autism, obsessive-compulsive or other neurodevelopmental disorder, illness during testing or placement on stimulant medication for ADHD. The final sample consisted of 1312 individuals: 255 monozygotic (MZ) twin pairs, 183 same-sex dizygotic (DZ) and 206 opposite-sex DZ twin pairs, as well as 24 singletons coming from pairs with one of the twins excluded. Data for the 24 singleton twins were also used in the structural equation modelling (see Neale et al. 2003). Participants were invited to our research centre for cognitive assessment (see Kuntsi et al. 2006), where ratings on the Conners' scale and the reading difficulties questionnaire were collected from parents. Teachers' ratings on the Conners' scale were obtained through post.

The mean age of the sample was $8.83(\mathrm{SD}=0.67)$, and half of the sample were girls $(N=663,50.5 \%)$. Children's IQs ranged from 70 to $158(\mathrm{M}=109.34, \mathrm{SD}=14.72)$. Parents of all participants gave informed consent following procedures approved by the Institute of Psychiatry Ethical Committee.

\section{Measures}

Wechsler Intelligence Scales for Children, Third Edition (WISC-III; Wechsler 1991) The vocabulary, similarities, picture completion and block design subtests from the WISC-III were used to obtain an estimate of the child's IQ (prorated following procedures described by Sattler (1992)).
Ratings of Inattention and Hyperactivity-Impulsivity Parents and teachers were asked to complete the Long Versions of the Conners' Parent and Teacher Rating Scales (Conners et al. 1998a,b). Teacher ratings were collected from the main class teacher for each child. Previous analyses on the TEDS sample indicated that the majority of twins had been rated by the same teacher (Saudino et al. 2005). In a study looking at scholastic achievement and hyperactivity/inattention in the TEDS parent sample, the aetiology of the covariance was similar for ratings provided by the same or different teachers or parents (Saudino and Plomin 2007). From both scales, we used the 9-item inattention and 9-item hyperactivity-impulsivity DSM-IV symptoms sub-scales. Inter-rater agreement for parent and teacher ratings was .46 $(p<.001)$ for inattention and $.40(p<.001)$ for hyperactivityimpulsivity, which are comparable to those obtained in previous studies (Saudino et al. 2005; Thapar et al. 2000). We created DSM-IV composite inattention and hyperactivityimpulsivity scores by summing up standardized parent and teacher ratings on the corresponding subscales. Teacher ratings were missing for 151 individuals and parent ratings for two individuals. Those with missing teacher ratings on the Conners' scale did not significantly differ from the rest of the sample on the reading difficulties questionnaire $(F(1,667)=$ $0.61, p=.43)$, in IQ $(\mathrm{F}(1,667)=3.55, p=.06)$ or parent hyperactivity-impulsivity ratings $(F(1,666)=3.49, p=.06)$, but were slightly older $(\mathrm{M}=9.12, \mathrm{SD}=0.71 ; F(1,667)=$ $17.88, p<.001)$ and had slightly higher parent inattention ratings $(\mathrm{M}=7.18, \mathrm{SD}=5.82 ; F(1,666)=5.01, p=.026)$ (corrected for the inclusion of non-independent data from twin pairs; Williams 2000). To avoid excluding existing data from these 153 individuals and consequently reducing the power of our study, and under the assumption that teacher data were missing at random, we imputed missing parent and teacher ratings using the existing teacher or parent ratings, respectively, with the "impute" command in STATA (version 10.0; StataCorp, 2007). In a few cases, missing responses to individual items in the Conners' subscales were pro-rated: a summary score based on the mean of individual questions on the rest of the subscale was used if there was more than $75 \%$ completion for each subscale. In our sample, $11.8 \%$ of the participants had parent ratings and $4.6 \%$ of the participants had teacher ratings on the DSM-IV ADHD total scale indicating clinical significance (using as a cut-off a $T$-score> 65 as indicated in the manual) (Conners 1997). These estimates match or exceed the estimated ADHD prevalence rate in the population (Ford et al. 2003; Polanczyk et al. 2007).

Reading Difficulties Questionnaire (RDQ; Martin et al. 2006; Rommelse et al. 2009; Willcutt et al. 2010b) This 6item parent rating scale is part of an instrument screening for learning disorders. On a scale which ranges from 1 
("Never/not at all") to 5 ("Always/a great deal"), parents are asked to report to what extent their child has difficulties with spelling, learning letter names or phonics (sounding words out), and to what extent their child reads slowly, below expectancy level or has required extra help at school. In the validation study, using four independent referred and general population samples $(N=4158)$, all items loaded on a single factor and the scale showed excellent internal consistency (mean Cronbach's $\alpha=.90$ ) and high inter-rater $(r=.83)$ and 1-year test-retest $(r=.81)$ reliabilities (Willcutt et al. 2010b). In that study RDQ showed high correlations with a range of objective reading and spelling measures (overall $r=.64$; CI:.60 to .68) but low correlations with measures of other learning difficulties $(r=.07-.024)$, attesting to its good criterion and discriminant validity (Willcutt et al. 2010b). In our sample (using data collected as part of the TEDS project, Trouton et al. 2002), the RDQ showed similarly high correlations with a measure of word reading efficiency $(r=-.63, p<.001, N=301$, unpublished observations; Test of word reading efficiency, Torgesen et al. 1999) and teacher ratings for reading attainment $(r=-.58, p<.001$, $N=975$; unpublished observations). Moreover, RDQ scores have shown high heritability $\left(h^{2}=53 \%\right.$ to $83 \%$ ) and high genetic correlations $(-.71$ to -.89$)$ with a composite measure of reading performance (Astrom et al. 2009; Martin et al. 2006). Parent and teacher ratings of inattention and hyperactivity-impulsivity showed remarkably similar correlations with RDQ scores (inattention: parents:.41 (CI95:.37 to .46), teachers:.47 (CI95:.45 to .51); hyperactivity-impulsivity: parents:.22 (CI95:.17 to .23), teachers:.17 (CI95:.11 to .18)).

\section{Analyses}

Overview of the Twin Method In univariate analyses, correlations between members of a twin pair for each trait are used to apportion phenotypic variance to additive genetic (A), dominant genetic (D) or shared environment (C), and child-specific environment (E) components (which also subsumes measurement error) (Neale and Cardon 1992; Plomin et al. 2001). Based on the assumptions that (a) MZ twins are genetically identical and therefore share $100 \%$ of genetic variation, whereas DZ twins share, on average, $50 \%$ of their segregating alleles contributing to $\mathrm{A}$ and $25 \%$ contributing to $\mathrm{D}$, and (b) both $\mathrm{MZ}$ and $\mathrm{DZ}$ pairs share $100 \%$ of their $\mathrm{C}$ but are discordant for $\mathrm{E}$, the phenotypic variance for a trait is partitioned into constituent $\mathrm{A}, \mathrm{D}$ or $\mathrm{C}$ and $\mathrm{E}$ influences. Greater phenotypic similarity between $\mathrm{MZ}$ twins compared to $\mathrm{DZ}$ twins suggests genetic influences on trait variance. If the phenotypic similarity of $\mathrm{MZ}$ twins is more than twice that of DZ twins, this suggests the presence of $\mathrm{D}$, otherwise only $\mathrm{A}$ is suggested. DZ twin correlations greater than half the MZ twin correlations suggest the presence of $\mathrm{C}$. The extent to which MZ twins are not $100 \%$ concordant for a trait reflects E (Rijsdijk and Sham 2002).

Structural equation modelling provides a tool for the formal estimation of variance components $(\mathrm{A}, \mathrm{C} / \mathrm{D}$ and $\mathrm{E}$ parameters) and for testing alternative models describing possible component contributions to trait variance or covariance. When only twin pairs reared together are used, the available information allows the estimation of only a $\mathrm{C}$ or D component at a time. In multivariate genetic analyses, as well as partitioning the phenotypic variance of single traits, it is also the covariance between traits that is decomposed into $\mathrm{A}, \mathrm{C} / \mathrm{D}$ and $\mathrm{E}$ influences following exactly the same logic as above and using the ratio of MZ:DZ differences in cross-twin cross-trait correlations, (e.g. inattention symptoms in twin 1 with reading difficulties in twin 2) (Rijsdijk and Sham 2002).

As multivariate models have increased power over univariate models (Schmitz et al. 1998), we do not present parameter estimates from univariate models. Univariate modelling was used to inform the choice of parameters for the multivariate models (e.g. the choice of $\mathrm{C}$ or $\mathrm{D}$ parameters) and to test for sex effects.

Structural Equation Modelling Structural equation modelling was performed using Mx (Neale et al. 2003). Models were fitted to age- and sex-regressed standardized residual scores, which were logarithmically transformed to minimize skewness. All estimates are provided with 95\% confidence intervals (the inclusion of zero indicates nonsignificance). The relative goodness of fit of the competing hierarchical (or nested) models was assessed using a likelihood ratio test. This was computed as the difference in the $-2 \mathrm{LL}$ statistics of two models, which is distributed as a $\chi^{2}$ with degrees of freedom ( $\mathrm{df}$ ) equal to the difference in the parameters estimated with each model. A significant $\chi^{2}$ suggests a significant deterioration in fit for the more constrained model; if the $\chi^{2}$ is not significant, the model with the fewer parameters is preferred for being more parsimonious. In the case of multivariate genetic analyses with large samples, the $\chi^{2}$ difference from the saturated model is likely to be significant. In such cases, as well as when comparing models that are not nested, Akaike's information criteria (AIC) can be used to assess the relative fit of models. The lowest AIC value indicates the best fitting model, given the data and the set of candidate models (Wagenmakers and Farrell 2004).

Saturated Phenotypic Model This model fully describes the data using the maximum number of free parameters and provides a baseline comparison for subsequent genetic models. We constrained this model in accordance with the 
assumptions of the genetic method (that is, means and variances within traits and phenotypic correlations across traits were equated across twins in a pair and zygosity groups) to obtain phenotypic correlations representative of the whole sample while taking into account the nonindependence of the data (i.e. data of related subjects).

Sex Effects Qualitative sex differences are found where the nature of the $\mathrm{A}, \mathrm{C} / \mathrm{D}$ and $\mathrm{E}$ influences differs, i.e. different genes or different environmental influences underlie the variance in the trait for males and females. The data indicate quantitative sex differences if the magnitude of $\mathrm{A}$, $\mathrm{C} / \mathrm{D}$ and $\mathrm{E}$ influences underlying a trait are significantly different for males and females. Scalar sex differences are found where only unstandardized $\mathrm{A}, \mathrm{D} / \mathrm{C}$ and $\mathrm{E}$ estimates differ (but standardized estimates are the same), due to variance differences in the trait distribution between males and females. There were neither qualitative nor quantitative sex differences underlying the variance in traits, although scalar differences were observed for reading difficulties, and inattention and hyperactivity-impulsivity symptoms. Therefore, in the multivariate modelling male phenotypic variances for these traits were pre- and post-multiplied by a scaling factor. As there are no significant qualitative or quantitative differences in variance components between the sexes, MZ and DZ correlations are not presented for each sex. However, given the scalar differences between the sexes, means and standard deviations are broken down into sex- and zygosity-specific groups (Table 1).

Parameter Selection for the Multivariate Models In the univariate analyses, an ACE model provided the best fit for IQ, while ADE models (with scalar sex differences) fitted best for the remaining three phenotypes (as we would predict from the MZ:DZ ratios of cross-twin correlations for these traits, Table 1). In this study we were interested to assess the contribution of broad-sense shared genetic influences to the covariation between reading difficulties and inattention (that is, not distinguishing between A and D effects), and the extent to which they are independent from genetic effects also shared with IQ. Therefore, in the multivariate models we parsed the variance contributing to the covariation among the four phenotypes into $\mathrm{A}$ and $\mathrm{E}$ components, with A reflecting broad-sense genetic effects. Due to the lack of qualitative or quantitative sex differences in the univariate analyses beyond scalar differences, the computational intensity of modelling sex effects and additional power issues (Neale et al. 2006), only scalar differences between males and females were allowed in the multivariate models.

Multivariate Genetic analyses A Cholesky triangular decomposition, which postulates a series of hierarchical genetic (A1-A4) and child-specific environment (E1-E4) factors, was used (Fig. 1). The order of the traits in the Cholesky model was decided a priori, with a view to estimating the aetiological influences that contribute to the covariance between reading difficulties and inattention symptoms independent of the other traits. A different ordering of the traits would produce the same fit of the model, but address different questions. The Cholesky model can be converted to the mathematically equivalent correlated factors solution (Fig. 2; Loehlin 1996), in which the order of traits is of no importance. This mathematical solution allows the estimation of the extent to which the same genes or environments contribute to the covariation between traits (i.e. the genetic and environmental correlations), irrespective of the extent to which they are shared with other traits in the model.

For instance, in the Cholesky model, the proportion of the covariance between reading difficulties and inattention symptoms due to common genes (or environmental factors) which are not shared with hyperactivity-impulsivity symptoms and/or IQ can be estimated as the product of the paths linking these phenotypes with latent factor $\mathrm{A} 3$ and dividing by their covariance. In the same model, the proportion of the variance in reading difficulties which is not due to genetic (or environmental) effects shared with any of the other traits measured in this study is estimated by dividing the square of the path linking RDQ with latent genetic factor $\mathrm{A} 4$ by the variance in RDQ scores.

Two additional multivariate models were employed to address the question of whether the covariance between the four traits in our study could be attributed to genetic and child-specific environment effects that are common to all, either directly (common factor, independent-pathway model, Fig. 3a), or through a common latent factor (commonfactor, common-pathway model, Fig. 3b).

\section{Results}

Aim 1: Are the phenotypic and genetic correlations between reading difficulties and ADHD inattention symptoms larger compared to hyperactivity-impulsivity symptoms?

A medium phenotypic correlation between reading difficulties and inattention symptoms was observed, which was substantially and significantly higher than the correlation with hyperactivity-impulsivity symptoms $(p<.001)$ (Table 2). The association between IQ and reading difficulties was similar to what has been previously reported in the larger TEDS sample using a composite 
Table 1 Cross-Twin Correlations (with 95\% Confidence Intervals in Brackets) and Means (and Standard Deviations) for and Across IQ, Inattention, Hyperactivity-Impulsivity and Reading Difficulties Ratings

\begin{tabular}{|c|c|c|c|c|c|c|c|c|}
\hline \multirow[t]{2}{*}{ Cross-twin correlations } & \multicolumn{2}{|l|}{ IQ } & \multicolumn{2}{|c|}{ Hyperactivity-impulsivity ${ }^{\mathrm{a}}$} & \multicolumn{2}{|l|}{ Inattention $^{\mathrm{a}}$} & \multicolumn{2}{|c|}{ Reading difficulties } \\
\hline & $\mathrm{MZ}$ & $\mathrm{DZ}$ & $\mathrm{MZ}$ & $\mathrm{DZ}$ & $\mathrm{MZ}$ & $\mathrm{DZ}$ & $\mathrm{MZ}$ & $\mathrm{DZ}$ \\
\hline IQ & $.80(.75, .83)$ & $.49(.41, .56)$ & & & & & & \\
\hline $\begin{array}{l}\text { Hyperactivity- } \\
\text { impulsivity }^{\mathrm{a}}\end{array}$ & $-.06(-.12, .01)$ & $-.06(-.11, .01)$ & $.70(.63, .75)$ & $.28(.19, .37)$ & & & & \\
\hline Inattention $^{\mathrm{a}}$ & $-.13(-.19,-.06)$ & $-.01(-.08, .06)$ & $.45(.38, .50)$ & $.16(.08, .24)$ & $.57(.49, .65)$ & $.10(.00, .19)$ & & \\
\hline Reading difficulties & $-.33(-.39,-.27)$ & $-.13(-.20,-.05)$ & $.19(.13, .26)$ & $.07(.00, .14)$ & $.40(.33, .45)$ & $.08(.00, .15)$ & $.77(.71, .81)$ & $.16(.06, .26)$ \\
\hline Males Mean $(\mathrm{SD})^{\mathrm{b}}$ & $109.45(14.64)$ & $111.17(15.40)$ & $11.06(8.61)$ & $11.53(9.64)$ & $12.70(8.95)$ & $14.25(11.14)$ & $10.79(6.33)$ & $11.47(6.66)$ \\
\hline Females Mean $(\mathrm{SD})^{\mathrm{b}}$ & $107.62(14.48)$ & $108.56(14.05)$ & $6.77(5.93)$ & $7.29(6.46)$ & $7.84(6.53)$ & $9.01(7.86)$ & $9.90(4.75)$ & $9.82(5.06)$ \\
\hline
\end{tabular}

Significant correlations in bold

' Summed parent and teacher Conners' DSM-IV subscale ratings

${ }^{\mathrm{b}}$ Raw scores, except for IQ (IQ raw scores were standardised to a mean of 100 and SD of 15, following procedures described in Wechsler (1991))

index of reading ability $(r=.43$; Harlaar et al. 2005a). The correlation between IQ and ADHD inattention symptoms was small but significant, while the correlation with hyperactivity-impulsivity symptoms, although also significant, was less than half the size of the association with inattention. Heritability estimates ranged from 55\% for inattention to $74 \%$ for reading difficulties (Table 3 ). The genetic correlation between reading difficulties and inattention was moderately high at $0.60,2.5$ times the size of the genetic correlation with hyperactivity-impulsivity (Table 3 ). The phenotypic correlation of reading difficulties with both inattention and hyperactivity-impulsivity symptoms was largely attributable to shared genetic effects $(75 \%$ and $92 \%$ respectively; Table 3).

Aim 2: To what extent do genes that are also shared with IQ and/or hyperactivity-impulsivity explain the covariance between reading difficulties and inattention symptoms?

Comparing the AIC values of the three multivariate models, including the common-pathway and independentpathway models, showed that the ACE-AE Cholesky model provided the best fit to the data (Table 4). This indicated
Fig. 1 Multivariate Cholesky triangular decomposition with unstandardized parameter estimates. The best-fitting ACE (IQ)-AE model is presented (for twin one only)

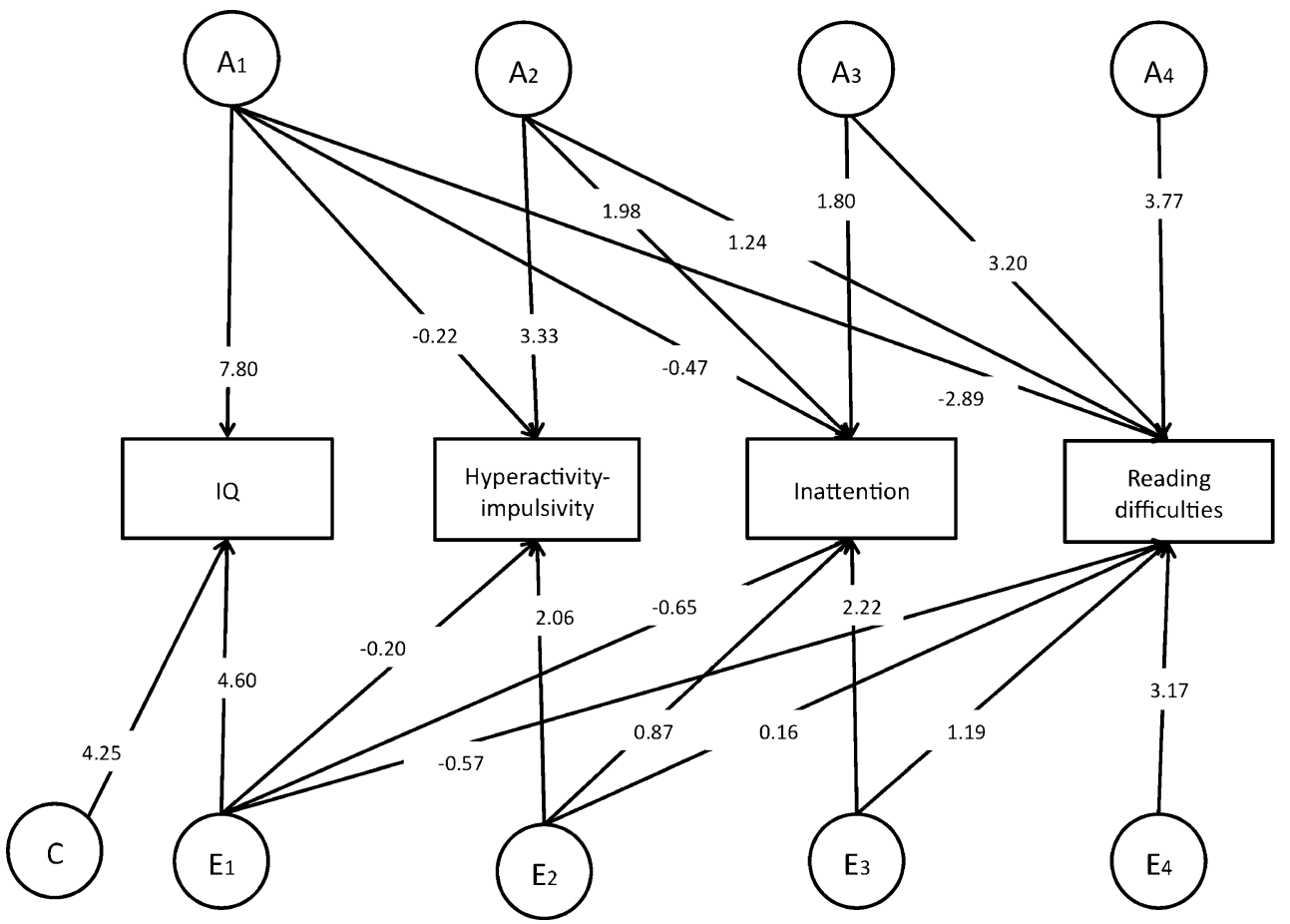




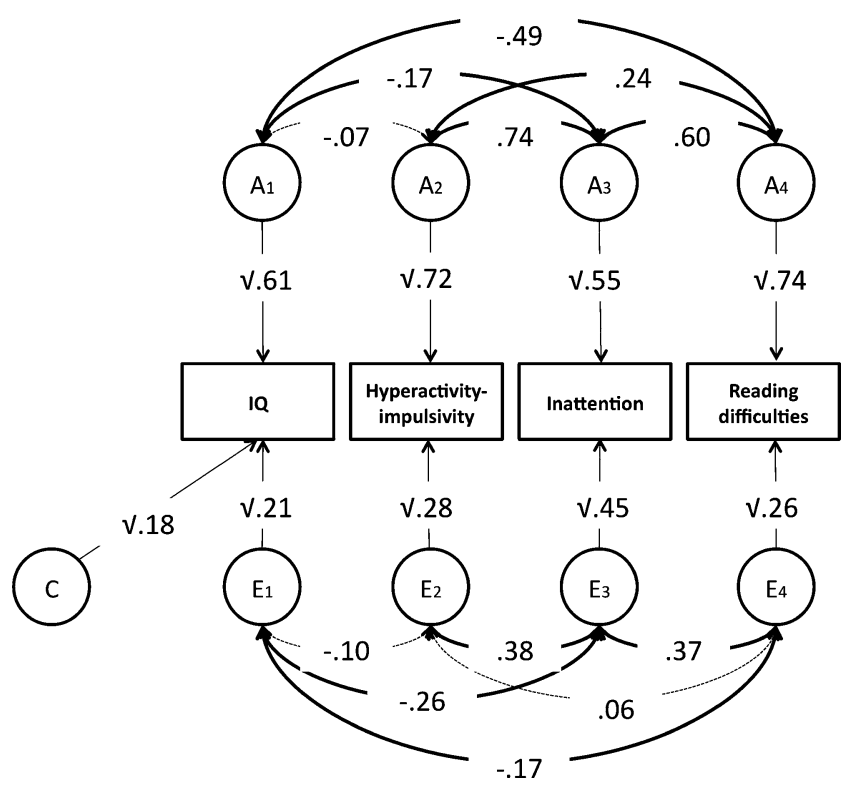

Fig. 2 Correlated factors solution of the best fitting ACE(IQ)-AE multivariate Cholesky decomposition model presented in Fig. 1 (for twin one only). Path estimates presented as square roots are the unstandardized parameter estimates (the basis of the square root provides the standardized estimate). Bidirectional arrows between latent genetic (A1-A4) and child-specific environment (E1-E4) factors show the genetic $\left(r_{g}\right)$ and child-specific environment $\left(r_{e}\right)$ correlations between them, respectively. Dotted arrows denote nonsignificant estimates

that the covariance between the four phenotypes could not be best explained by genetic and environmental factors that are common among all traits. Using the parameter estimates from the best-fitting Cholesky decomposition model (Fig. 1), we estimated that $45 \%$ of the covariance between reading difficulties and inattention was due to genetic effects not shared with any of the other phenotypes: $(3.20 * 1.80) /[3.20 * 1.80+1.24 * 1.98+(-2.89) *(-0.47)$ $+2.22 * 1.19+0.16 * 0.87+(-0.57) *(-0.65)]$. Similarly, we calculated that a fifth $(19 \%)$ of the covariance was due to genetic effects shared with both inattention and hyperactivity-impulsivity, but not IQ, and only $11 \%$ of the covariance was due to genetic effects shared among all four phenotypes. These estimates added up to $75 \%$, which was the percentage of the phenotypic correlation between reading difficulties and inattention due to shared genetic effects (Table 3). The remaining $25 \%$ percent could be attributed to child-specific environment effects $(21 \%$ not being shared with hyperactivity-impulsivity or IQ).

Aim 3: To what extent can genetic and environmental effects shared with ADHD symptoms and IQ account for variance in reading difficulties?

Individual differences in reading difficulties scores were largely attributed to genetic factors (heritability $\mathrm{h}^{2}=74 \%$; Table 3). Of the total variance for reading difficulties, $31 \%$ $\left[3.77^{2} /\left(3.77^{2}+3.20^{2}+1.24^{2}+(-2.89)^{2}\right.\right.$ $\left.\left.+3.17^{2}+1.19^{2}+0.16^{2}+(-0.57)^{2}\right)\right]$ (or $42 \%$ of the heritability) was attributed to unique genetic effects (see Fig. 1), 22\% to genetic effects shared only with inattention (A3), $3 \%$ to genetic effects shared with both inattention and hyperactivity-impulsivity (A2), and $18 \%$ to genetic effects shared among all phenotypes (A1). Unique child—specific environment influences accounted for $22 \%$ of the total variance in reading difficulties, whereas the sum of childspecific environment influences shared with the other phenotypes accounted for only $4 \%$ of the total variance.

Aim 4: Are there possible gender differences in the aetiology for the covariation between reading difficulties and inattention symptoms?

The lack of qualitative and quantitative sex differences in the univariate analyses, together with the absence of any indication of sex differences in the cross-twin cross-trait correlations for reading difficulties and inattention symptoms between males (MZ: $r=.39,95 \%$ confidence intervals

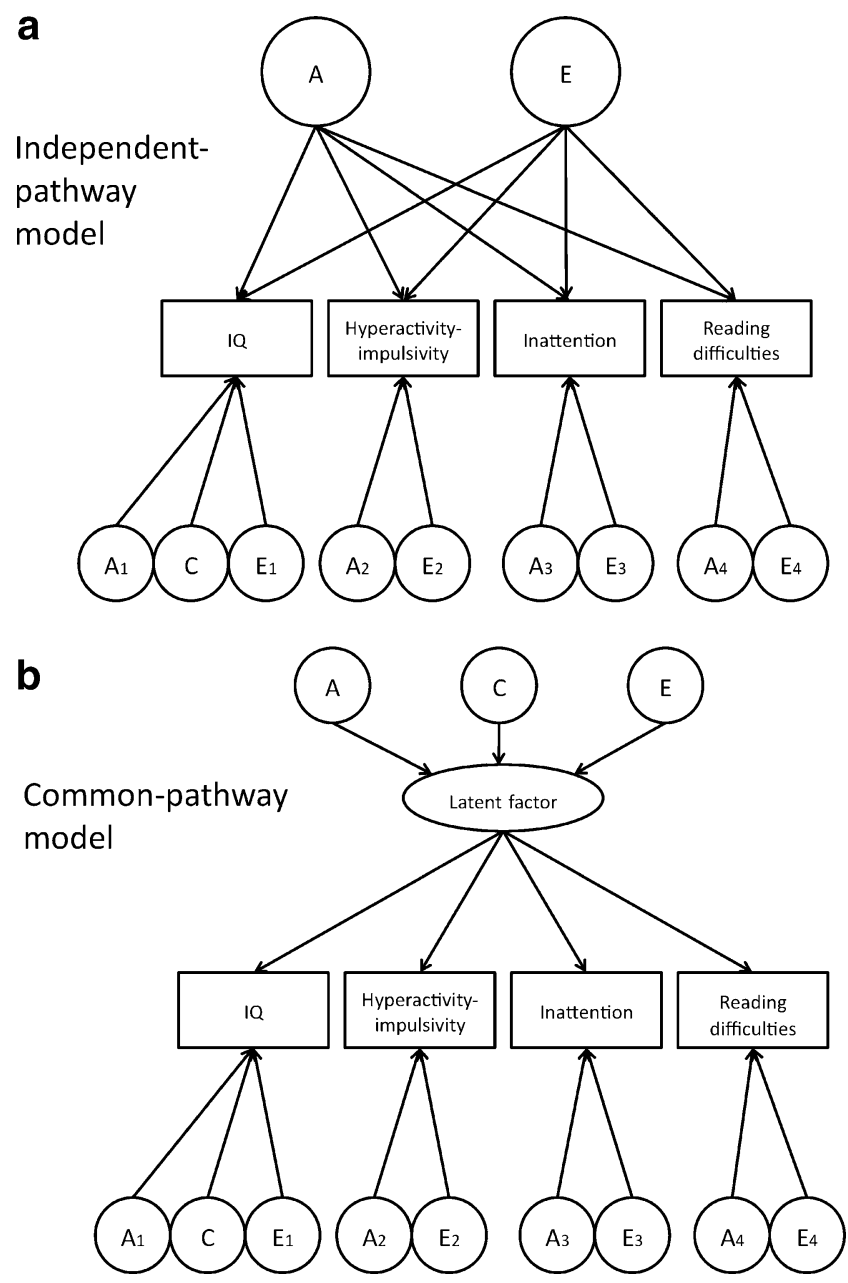

Fig. 3 Illustration of the multivariate independent pathways (a) and common pathway (b) ACE(IQ)-AE models which were compared to the multivariate Cholesky model presented in Fig. 1 
Table 2 Phenotypic Correlations (with 95\% Confidence Intervals in Brackets) Across IQ, Inattention, Hyperactivity-Impulsivity and Reading Difficulties Ratings

\begin{tabular}{lccr}
\hline & Reading difficulties & Inattention $^{\mathrm{a}}$ & Hyperactivity-impulsivity $^{\mathrm{a}}$ \\
\hline Inattention $^{\mathrm{a}}$ & $\mathbf{. 5 1}(.47, .55)$ & & $\mathbf{. 6 0}(.56, .64)$ \\
Hyperactivity-impulsivity $^{\mathrm{a}}$ & $\mathbf{. 2 2}(.16, .28)$ &.$- \mathbf{1 9}(-.24,-.13)$ & $-\mathbf{0 8}(-.14,-.02)$ \\
IQ &.$- \mathbf{3 7}(-.42,-.31)$ & \\
\hline
\end{tabular}

Significant correlations in bold

${ }^{\text {a }}$ Summed parent and teacher Conners' DSM-IV subscale ratings

(CI95):.31 to .46; DZ: $r=.02$, CI95: -.15 to .19) and females (MZ: $r=.41$, CI95:.34 to .47; DZ: $r=.04$, CI95: -.12 to .20 ), provided no indication for further testing this aim in the multivariate analysis.

\section{Discussion}

Using an unselected general population sample, we confirmed previous reports that reading difficulties show higher phenotypic and genetic correlations with ADHD inattention symptoms, compared to hyperactivityimpulsivity symptoms (Martin et al. 2006; Willcutt et al. 2000, 2007b). This study further showed, for the first time, that the covariance between reading difficulties and ADHD inattention symptoms is largely $(66 \%)$ driven by aetiological factors (genetic, 45\%, and child-specific environment, $21 \%$ ) that are not shared with IQ or hyperactivityimpulsivity. Almost half (47\%) of the variance in reading difficulties was attributed to components shared with other phenotypes, mainly genetic influences shared with inattention $(22 \%)$ or inattention, hyperactivity-impulsivity and IQ (18\%), attesting to the multifactorial nature of the deficits underlying reading disability (Bosse et al. 2007; Vellutino et al. 2004).

This study extends findings from bivariate twin studies that used extreme selected groups (Willcutt et al. 2000, $2007 \mathrm{~b}$ ) to the full distribution of ADHD symptom ratings and reading disability scores in the general population. The similarity of findings across selected and general population samples supports the notion that inattention and hyperactivity-impulsivity symptoms and reading disability are the tails of normally distributed traits, reflecting normally distributed risk factors in the population (Chen et al. 2008; Harlaar et al. 2005b; Levy et al. 1997; Shaywitz et al. 1992).

A novel finding in this study was that the aetiological factors linking reading difficulties with inattention symptoms were largely independent from factors affecting general cognitive ability. This is consistent with evidence

Table 3 Standardized Parameter Estimates (with 95\% Confidence Intervals) from the Correlated Factors Solution of the Full Cholesky Model Within and Across IQ, Hyperactivity-Impulsivity, Inattention and Reading Difficulties Ratings

\begin{tabular}{|c|c|c|c|c|}
\hline & IQ & Hyperactivity-impulsivity $^{\mathrm{a}}$ & Inattention $^{\mathrm{a}}$ & Reading difficulties ${ }^{\mathrm{a}}$ \\
\hline \multicolumn{5}{|c|}{ Genetic influences (broad sense) } \\
\hline IQ & $.61(.47, .76)$ & $-0.05(66 \%)$ & $-0.10(55 \%)$ & $-0.33(89 \%)$ \\
\hline Hyperactivity-impulsivity $^{\mathrm{a}}$ & $-.07(-.17, .04)$ & $.72(.66, .77)$ & $0.47(78 \%)$ & $0.18(92 \%)$ \\
\hline Inattention $^{\mathrm{a}}$ & $-.17(-.29,-.05)$ & $.74(.66, .81)$ & $.55(.45, .63)$ & $0.38(75 \%)$ \\
\hline Reading difficulties & $-.49(-.60,-.40)$ & $.24(.15, .33)$ & $.60(.51, .68)$ & $.74(.68, .79)$ \\
\hline \multicolumn{5}{|c|}{ Child-specific environmental influences } \\
\hline IQ & $.21(.17, .26)$ & $-0.02(34 \%)$ & $-0.08(45 \%)$ & $-0.04(11 \%)$ \\
\hline Hyperactivity-impulsivity $^{\mathrm{a}}$ & $-.10(-.22, .02)$ & $.28(.23, .34)$ & $0.13(22 \%)$ & $0.02(8 \%)$ \\
\hline Inattention $^{\mathrm{a}}$ & $-.26(-.38,-.14)$ & $.38(.27, .48)$ & $.45(.37, .55)$ & $0.13(25 \%)$ \\
\hline Reading difficulties & $-.17(-.29,-.04)$ & $.06(-.06, .18)$ & $.37(.26, .48)$ & $.26(.20, .32)$ \\
\hline \multicolumn{5}{|c|}{ Shared environment influences (IQ only) } \\
\hline IQ & $.18(.04, .31)$ & & & \\
\hline
\end{tabular}

The heritability, child-specific environment influences and shared environment influences of each variable is given in bold in the diagonal. The genetic and child-specific environment correlations (and 95\% confidence intervals) between pairs of variables are given below the diagonal. The contributions of genetic and child-specific environment influences to the phenotypic correlations between variables are given above the diagonal, with the percentage of the phenotypic correlations due to broad-sense genetic or child-specific environment effects in brackets

${ }^{\text {a }}$ Summed parent and teacher Conners' DSM-IV subscale ratings 
Table 4 Statistics for the Relative Fit of the Multivariate Genetic Models

\begin{tabular}{|c|c|c|c|c|c|c|c|c|c|c|c|c|}
\hline & Multivariate models & $-2 \mathrm{LL}$ & df & $\Delta \chi^{2}$ & $\Delta \mathrm{df}$ & $\mathrm{p}$ & AIC & $\Delta \chi^{2}$ & $\Delta \mathrm{df}$ & $\mathrm{p}$ & AIC & $\begin{array}{l}\text { Comparison } \\
\text { model }\end{array}$ \\
\hline 1 & Saturated & 32323.17 & 5024 & - & - & - & - & - & - & - & - & - \\
\hline 2 & ACE-AE (scalar) & 32596.76 & 5212 & 273.58 & 188 & $<.001$ & -102.417 & - & - & - & - & 1 \\
\hline 3 & $\begin{array}{l}\text { ACE/AE: common } \\
\text { pathway (scalar) }\end{array}$ & 32795.59 & 5218 & 472.42 & 194 & $<.001$ & 84.415 & 198.84 & 6 & $<.001$ & 186.84 & $1 / 2$ \\
\hline 4 & $\begin{array}{l}\text { ACE/AE: independent } \\
\text { pathways (scalar) }\end{array}$ & 32759.70 & 5216 & 436.52 & 192 & $<.001$ & 52.522 & 162.94 & 4 & $<.001$ & 154.94 & $1 / 2$ \\
\hline
\end{tabular}

Best-fitting model in bold

from behavioural genetic (Saudino and Plomin 2007) and longitudinal studies (Rabiner and Coie 2000; Rabiner and Malone 2004). Moreover, accumulating evidence from reading disability studies has challenged the role of IQ as a useful marker in the diagnosis of reading disability and the prognosis of outcome (Stuebing et al. 2002; Vellutino et al. 2004). For example, IQ-discrepancy scores did not distinguish cases according to the potential benefit they would receive from an intervention program (Vellutino et al. 2004; Vellutino et al. 2000). In a behavioural intervention study, teacher attention ratings predicted reading outcome better than verbal IQ did (Stage et al. 2003).

Another novel finding in this study was that childspecific environment factors (including possible error) were uniquely shared between reading difficulties and inattention symptoms, making a significant contribution (21\%) to their covariance. This confirms previous evidence from TEDS showing a child-specific environment contribution to the covariation between a brief ADHD measure and a composite measure of teacher-assessed scholastic achievement (including reading) (Saudino and Plomin 2007). Other studies, though, have reported minimal or no contributions of child-specific environment influences (Martin et al. 2006; Willcutt et al. 2000). Possibly, the use of the full range of scores that is available with an unselected general population sample and the multivariate design may have increased power to detect this effect. Saudino and Plomin (2007) suggested that such factors are likely to operate across family and school environments. An intriguing prospect for future research would be to replicate this finding and identify such factors using objective readings measures, as they might provide useful targets for intervention.

Consistent with previous reports (Saudino and Plomin 2007; Willcutt et al. 2000), our findings did not provide any indication for gender differences in the aetiology of the covariance between reading difficulties and inattention symptoms. Further, while our data confirmed the low phenotypic and genetic correlations between reading difficulties and hyperactivity-impulsivity symptoms, it suggested that the phenotypic association was almost entirely due to shared genetic effects $(92 \%)$, unlike previous reports (Willcutt et al. 2000, 2007b). It is possible that the use of the full range of scores in an unselected sample may have made possible the detection of this effect in the present study.

The evidence from this and previous studies (Martin et al. 2006; Willcutt et al. 2000, 2007b) is supportive of the idea that pleiotropic gene effects drive the covariance between inattention symptoms and reading difficulties. Further support is provided by molecular genetic studies, which have identified genetic variants likely to increase susceptibility to both reading disability and ADHD or show bivariate linkage to both disorders (Couto et al. 2009; Gayan et al. 2005; Loo et al. 2004; Wigg et al. 2008; Willcutt et al. 2002). Current twin and genetic data cannot distinguish, though, between different causal pathways; phenotypic covariance could result either from deficits in distinct neurocognitive mechanisms underlying each disorder, or deficits in common processes acting as vulnerability factors for both disorders, or both. Existing evidence from neuropsychological, medical treatment and behavioural intervention studies, while consistent with the idea of pleiotropic gene effects, is supportive of both possible patterns of causal relatedness.

Neuropsychological deficits in the comorbid group are mostly a combination of deficits observed when either disorder is present alone (Bental and Tirosh 2007; Rommelse et al. 2009; Shanahan et al. 2006; Willcutt et al. 2001, 2005). Processing speed and rapid naming emerge as strong candidates for shared risk factors, sharing all the common genetic influences contributing to the covariance between performance in objective reading tests and ADHD symptoms (Willcutt et al. 2010a). The same executive and motor endophenotypes have also been associated with both reading difficulties and ADHD (Rommelse et al. 2009).

Pharmacological studies have shown that despite improvements in ADHD symptoms, methylphenidate and atomoxetine effects on reading performance depended on the nature of the drug, and possibly the reading test that was used. Methylphenidate improved reading performance only in cases of reading disability comorbid with ADHD, despite similar improvements in inattention symptoms in single- 
disorder groups (Keulers et al. 2007). Similarly, a behavioural intervention program failed to improve reading performance only in those cases with both inattention symptoms and reading difficulties (Rabiner and Malone 2004). This evidence is suggestive of deficits in neurocognitive processes specific to the comorbid cases. Improvement in reading performance effected by atomoxetine treatment either did not correlate (or did so weakly) with improvement in ADHD symptoms (Sumner et al. 2009), or atomoxetine did not affect reading performance despite reducing ADHD symptoms (de Jong et al. 2009). This dissociation of atomoxetine effects on reading performance and ADHD symptoms suggests that distinct neurocognitive mechanisms may also contribute to the covariance between these traits.

Nevertheless, alternative explanations would also be consistent with a shared genes account. Methodological/ sampling issues, such as symptom overlap or shared method variance could mimic shared gene effects. The similarity of findings across studies using objective measures (Willcutt et al. 2000, 2007b) or parent ratings (this study and Martin et al. 2006) of reading difficulties makes it unlikely that such factors made an important contribution in this study. The use of only parent ratings of reading difficulties is a limitation of this study though. Crossassortative mating could be another possible confounding factor, yet initial evidence (Faraone et al. 1993) was not replicated (Friedman et al. 2003). Besides, cross-assortative mating would actually decrease estimates of shared genetic effects (Willcutt et al. 2000); evidently, this cannot have played an important role in this study.

Another possible explanation that would mimic shared gene effects is the phenocopy hypothesis, whereby disorder $\mathrm{B}$ is caused by the deficits associated with disorder $\mathrm{A}$, in the absence of the normal aetiological antecedents for the former (Pennington et al. 1993). Initially, based on the resemblance of the neurocognitive profile of the comorbid group with that of the pure reading disability group, it was suggested that ADHD is a secondary outcome of reading disability (Pennington et al. 1993). This hypothesis was not supported by later neuropsychological studies though (discussed earlier), or by evidence from separate lines of research. First, it is not consistent with evidence for small to moderate phenotypic and genetic correlations between inattention symptoms and prereading skills in preschool children, before the onset of formal reading instruction (Willcutt et al. 2007a,b). Second, ADHD symptom ratings before or at school entry predicted scholastic achievement in later years (Fantuzzo et al. 2003; Horn and Packard 1985; Merrell and Tymms 2001; Newman et al. 1998; Rabiner and Coie 2000). Third, this and other studies have found that parent as well as teacher ratings of ADHD symptoms predict reading difficulties, showing that this association was not restricted to the classroom (Fergusson and Horwood 1992; Saudino and Plomin 2007).

Yet this evidence is not inconsistent with the hypothesis that attention deficits could lead to reading difficulties. This idea makes intuitive sense, as it is plausible that inattention problems might interfere with reading instruction. It is known that inadequate experience or instruction in reading accounts for most cases of early reading difficulties, which can be rectified through additional tutoring (Vellutino et al. 2004). Such deficiencies would mimic deficits observed in cases of pure reading disability, which reflect cognitive deficits of biological origin (Vellutino et al. 2004). Inattention symptoms do indeed moderate the effect of early tutoring on reading development (Stage et al. 2003), and studies have shown that early inattention deficits could predict later reading achievement even after controlling for concurrent reading ability (Rabiner and Coie 2000; Rabiner and Malone 2004). In particular, Rabiner and Coie (2000) found that one third of a group of inattentive kindergarten children whose standardized reading achievement scores at grade 5 were substantially ( $>1 \mathrm{SD}$ ) below those of their peers had normal reading scores at the post-kindergarten assessment. However, existing evidence suggests that reading difficulties in the context of inattention symptoms may not be caused by inadequate tutoring, given the failure of a behavioural intervention program to improve reading performance only in the comorbid cases (Rabiner and Malone 2004).

The findings from the current study can only apply to reading difficulties and ADHD inattention symptoms as reflected in parent and teacher ratings; they cannot be extrapolated to any specific process in either domain. ADHD inattention ratings represent pervasive inattentiveness across different domains in real life over an extended period of time. Therefore our conclusions cannot be extended to any specific cognitive attention process, as overt behavioural problems cannot be linked in a simple and direct manner to possible underlying deficits in cognitive attention processes, while similar manifestations of inattention problems may reflect diverse cognitive deficits (Marzocchi et al. 2009; Warner-Rogers et al. 2000). Studies using specific cognitive attention measures may lead to different conclusions regarding the extent of shared aetiological influences with IQ, depending on what particular measure in used (Zumberge et al. 2007).

It is important to understand the causal links between inattention problems or deficits in cognitive attention processes and the development of normal reading skills or the act of reading. Reading disability is a multifactorial disorder (Bosse et al. 2007; Vellutino et al. 2004), and for behavioural interventions to be effective they need to address the specific aetiological factors involved in each 
case (e.g. focusing on self-regulation versus targeting a specific neurocognitive process) (Rabiner and Malone 2004; Stage et al. 2003). Inattention is unlikely to be associated with reading difficulties only at the behavioural level and, in line with existing research, our findings are consistent with the idea that specific neurocognitive processes underlie the covariance between these two traits, which reflects shared genetic and child-specific environment influences that are largely independent from IQ. Indeed, cognitive attentional processes are being recognized as being involved in many stages of the reading process (Bosse et al. 2007; Reynolds and Besner 2006; Shaywitz and Shaywitz 2008; Vidyasagar and Pammer 2010). In the future we need evidence from longitudinal twin studies, measuring objectively a range of specific reading skills as well as of processes likely to contribute to behavioural inattention problems. Such studies will identify with greater specificity the neurocognitive processes that link behavioural inattention with deficits in specific reading skills, and examine causal relationships between these traits though development, as well as examine whether the contribution of IQ differs throughout development.

Acknowledgements The Study of Activity and Impulsivity Levels in children (SAIL) is funded by a project grant from the Wellcome Trust (GR070345MF). Yannis Paloyelis is supported by a studentship from the Medical Research Council. Thank you to all who make this research possible: the TEDS-SAIL families, who give their time and support so unstintingly; Rebecca Gibbs, Hannah Rogers, Eda Salih, Greer Swinard, Kate Lievesley, Kayley O'Flynn, Suzi Marquis and Rebecca Whittemore; and everyone on the TEDS team.

\section{Declaration of Interest None}

Open Access This article is distributed under the terms of the Creative Commons Attribution Noncommercial License which permits any noncommercial use, distribution, and reproduction in any medium, provided the original author(s) and source are credited.

\section{References}

Alarcon, M., \& DeFries, J. C. (1997). Reading performance and general cognitive ability in twins with reading difficulties and control pairs. Personality and Individual Differences, 22(6), 793803.

American Psychiatric Association (APA). (2000). Diagnostic and statistical manual of mental disorders, 4 edition, text revision (4th ed.). Washington: APA.

Astrom, R., DeFries, J. C., Pennington, B., Wadsworth, S., \& Willcutt, E. G. (2009). Etiology of covariation between a parent-report screening measure and reading performance. Behavior Genetics, 39(6), 634.

August, G. J., \& Garfinkel, B. D. (1990). Comorbidity of ADHD and reading disability among clinic-referred children. Journal of Abnormal Child Psychology, 18(1), 29-45.

Bental, B., \& Tirosh, E. (2007). The relationship between attention, executive functions and reading domain abilities in attention deficit hyperactivity disorder and reading disorder: a comparative study. Journal of Child Psychology and Psychiatry, 48(5), 455-463.

Bosse, M. L., Tainturier, M. J., \& Valdois, S. (2007). Developmental dyslexia: the visual attention span deficit hypothesis. Cognition, 104(2), 198-230.

Byrne, B., Coventry, W. L., Olson, R. K., Hulslander, J., Wadsworth, S., DeFries, J. C., et al. (2008). A behaviour-genetic analysis of orthographic learning, spelling and decoding. Journal of Research in Reading, 31(1), 8-21.

Chen, W., Zhou, K., Sham, P., Franke, B., Kuntsi, J., Campbell, D., et al. (2008). DSM-IV combined type ADHD shows familial association with sibling trait scores: a sampling strategy for QTL linkage. American Journal of Medical Genetics. Part B: Neuropsychiatric Genetics, 147B(8), 1450-1460.

Conners, C. K. (1997). Conners' Rating Scales-Revised. Technical Manual. New York: MHS.

Conners, C. K., Sitarenios, G., Parker, J. D., \& Epstein, J. N. (1998a). The revised Conners' Parent Rating Scale (CPRS-R): factor structure, reliability, and criterion validity. Journal of Abnormal Child Psychology, 26(4), 257-268.

Conners, C. K., Sitarenios, G., Parker, J. D., \& Epstein, J. N. (1998b). Revision and restandardization of the Conners Teacher Rating Scale (CTRS-R): factor structure, reliability, and criterion validity. Journal of Abnormal Child Psychology, 26(4), 279-291.

Couto, J. M., Gomez, L., Wigg, K., Ickowicz, A., Pathare, T., Malone, M., et al. (2009). Association of attention-deficit/hyperactivity disorder with a candidate region for reading disabilities on chromosome 6p. Biological Psychiatry, 66(4), 368-375.

de Jong, C. G., Van De Voorde, S., Roeyers, H., Raymaekers, R., Allen, A. J., Knijff, S., et al. (2009). Differential effects of atomoxetine on executive functioning and lexical decision in attention-deficit/hyperactivity disorder and reading disorder. Journal of Child and Adolescent Psychopharmacology, 19(6), 699-707.

Dykman, R. A., \& Ackerman, P. T. (1991). Attention deficit disorder and specific reading disability: separate but often overlapping disorders. Journal of Learning Disabilities, 24(2), 96-103.

Fantuzzo, J., Bulotsky, R., McDermott, P., Mosca, S., \& Lutz, M. N. (2003). A multivariate analysis of emotional and behavioral adjustment and preschool educational outcomes. School Psychology Review, 32(2), 185-203.

Faraone, S. V., Biederman, J., Lehman, B. K., Keenan, K., Norman, D., Seidman, L. J., et al. (1993). Evidence for the independent familial transmission of attention deficit hyperactivity disorder and learning disabilities: results from a family genetic study. The American Journal of Psychiatry, 150(6), 891-895.

Fergusson, D. M., \& Horwood, L. J. (1992). Attention-deficit and reading-achievement. Journal of Child Psychology and Psychiatry and Allied Disciplines, 33(2), 375-385.

Ford, T., Goodman, R., \& Meltzer, H. (2003). The British Child and Adolescent Mental Health Survey 1999: the prevalence of DSMIV disorders. Journal of the American Academy of Child and Adolescent Psychiatry, 42(10), 1203-1211.

Friedman, M. C., Chhabildas, N., Budhiraja, N., Willcutt, E. G., \& Pennington, B. F. (2003). Etiology of the comorbidity between $\mathrm{RD}$ and ADHD: exploration of the non-random mating hypothesis. American Journal of Medical Genetics. Part B: Neuropsychiatric Genetics, 120B(1), 109-115.

Gayan, J., \& Olson, R. K. (2003). Genetic and environmental influences on individual differences in printed word recognition. Journal of Experimental Child Psychology, 84(2), 97-123.

Gayan, J., Willcutt, E. G., Fisher, S. E., Francks, C., Cardon, L. R., Olson, R. K., et al. (2005). Bivariate linkage scan for reading disability and attention-deficit/hyperactivity disorder localizes pleiotropic loci. Journal of Child Psychology and Psychiatry, 46(10), 1045-1056. 
Harlaar, N., Hayiou-Thomas, M. E., \& Plomin, R. (2005a). Reading and general cognitive ability: a multivariate analysis of 7-yearold twins. Scientific Studies of Reading, 9(3), 197-218.

Harlaar, N., Spinath, F. M., Dale, P. S., \& Plomin, R. (2005b). Genetic influences on early word recognition abilities and disabilities: a study of 7-year-old twins. Journal of Child Psychology and Psychiatry, 46(4), 373-384.

Haworth, C. M., Kovas, Y., Harlaar, N., Hayiou-Thomas, M. E., Petrill, S. A., Dale, P. S., et al. (2009). Generalist genes and learning disabilities: a multivariate genetic analysis of low performance in reading, mathematics, language and general cognitive ability in a sample of 800012 -year-old twins. Journal of Child Psychology and Psychiatry, 50(10), 1318-1325.

Horn, W. F., \& Packard, T. (1985). Early identification of learningproblems - a meta-analysis. Journal of Education \& Psychology, 77(5), 597-607.

Hottenga, J., \& Boomsma, D. I. (2008). QTL detection in multivariate data from sibling pairs. In B. Neale, M. A. Ferreira, S. E. Medland, \& D. Posthuma (Eds.), Statistical genetics. Gene mapping through linkage and association (pp. 239-264). New York: Taylor \& Francis.

Keulers, E. H., Hendriksen, J. G., Feron, F. J., Wassenberg, R., Wuisman-Frerker, M. G., Jolles, J., et al. (2007). Methylphenidate improves reading performance in children with attention deficit hyperactivity disorder and comorbid dyslexia: an unblinded clinical trial. European Journal of Paediatric Neurology, 11 (1), 21-28.

Kuntsi, J., Eley, T. C., Taylor, A., Hughes, C., Asherson, P., Caspi, A., et al. (2004). Co-occurrence of ADHD and low IQ has genetic origins. American Journal of Medical Genetics. Part B: Neuropsychiatric Genetics, 124B(1), 41-47.

Kuntsi, J., Rogers, H., Swinard, G., Borger, N., van der Meere, J., Rijsdijk, F., et al. (2006). Reaction time, inhibition, working memory and 'delay aversion' performance: genetic influences and their interpretation. Psychological Medicine, 36(11), 1613-1624.

Levy, F., Hay, D. A., McStephen, M., Wood, C., \& Waldman, I. (1997). Attention-deficit hyperactivity disorder: a category or a continuum? Genetic analysis of a large-scale twin study. Journal of the American Academy of Child and Adolescent Psychiatry, 36 (6), 737-744.

Loehlin, J. C. (1996). The Cholesky approach: a cautionary note. Behavior Genetics, 26(1), 65-69.

Loo, S. K., Fisher, S. E., Francks, C., Ogdie, M. N., MacPhie, I. L., Yang, M., et al. (2004). Genome-wide scan of reading ability in affected sibling pairs with attention-deficit/hyperactivity disorder: unique and shared genetic effects. Molecular Psychiatry, 9(5), 485-493.

Martin, N. C., Levy, F., Pieka, J., \& Hay, D. A. (2006). A genetic study of attention deficit hyperactivity disorder, conduct disorder, oppositional defiant disorder and reading disability: aetiological overlaps and implications. International Journal of Disability, Development and Education, 53(1), 21-34.

Marzocchi, G. M., Ornaghi, S., \& Barboglio, S. (2009). What are the causes of the attention deficits observed in children with dyslexia? Child Neuropsychology, 15(6), 567-581.

Merrell, C., \& Tymms, P. B. (2001). Inattention, hyperactivity and impulsiveness: their impact on academic achievement and progress. The British Journal of Educational Psychology, 71, 43-56.

Neale, M. C., \& Cardon, L. (1992). Methodology for genetic studies of twins and families. Dordrecht: Kluwer Academic.

Neale, M. C., Boker, S. M., Xie, G., \& Maes, H. H. (2003). Mx: Statistical modeling (6th ed.). Richmond: Department of Psychiatry.

Neale, M. C., Roysamb, E., \& Jacobson, K. (2006). Multivariate genetic analysis of sex limitation and $\mathrm{G} \times \mathrm{E}$ interaction. Twin Research and Human Genetics, 9(4), 481-489.
Newman, J., Noel, A., Chen, R., \& Matsopoulos, A. S. (1998). Temperament, selected moderating variables and early reading achievement. Journal of School Psychology, 36(2), 215-232.

Oliver, B., \& Plomin, R. (2006). Twins' Early Development Study (TEDS): a multivariate, longitudinal genetic Investigation of language, cognition and behavior Problems from childhood through adolescence. Twin Research and Human Genetics, 10 (1), 96-105.

Pennington, B., Groisser, D., \& Welsh, M. C. (1993). Contrasting cognitive deficits in Attention Deficit Hyperactivity Disorder versus Reading Disability. Developmental Psychology, 29, 511523.

Plomin, R., DeFries, J. C., McClearn, G. E., \& McGuffin, P. (2001). Behavioral Genetics (4th ed.). New York: Worth.

Polanczyk, G., de Lima, M. S., Horta, B. L., Biederman, J., \& Rohde, L. A. (2007). The worldwide prevalence of ADHD: a systematic review and metaregression analysis. The American Journal of Psychiatry, 164(6), 942-948.

Price, T. S., Freeman, B., Craig, I., Petrill, S. A., Ebersole, L., \& Plomin, R. (2000). Infant zygosity can be assigned by parental report questionnaire data. Twin Research, 3(3), 129-133.

Rabiner, D. L., \& Coie, J. D. (2000). Early attention problems and children's reading achievement: a longitudinal investigation. The Conduct Problems Prevention Research Group. Journal of the American Academy of Child and Adolescent Psychiatry, 39(7), 859-867.

Rabiner, D. L., \& Malone, P. S. (2004). The impact of tutoring on early reading achievement for children with and without attention problems. Journal of Abnormal Child Psychology, 32(3), 273284.

Reynolds, M., \& Besner, D. (2006). Reading aloud is not automatic: processing capacity is required to generate a phonological code from print. Journal of Experimental Psychology: Human Perception and Performance, 32(6), 1303-1323.

Rijsdijk, F. V., \& Sham, P. C. (2002). Analytic approaches to twin data using structural equation models. Briefings in Bioinformatics, 3 (2), 119-133.

Rommelse, N. N., Altink, M. E., Fliers, E. A., Martin, N. C., Buschgens, C. J., Hartman, C. A., et al. (2009). Comorbid problems in ADHD: degree of association, shared endophenotypes, and formation of distinct subtypes. Implications for a future DSM. Journal of Abnormal Child Psychology, 37(6), 793804.

Sattler, J. M. (1992). Assessment of Children: WISC-III and WPPSI-R Supplement. San Diego: Jerome M. Sattler.

Saudino, K. J., \& Plomin, R. (2007). Why are hyperactivity and academic achievement related? Child Development, 78(3), 972986.

Saudino, K. J., Ronald, A., \& Plomin, R. (2005). The etiology of behavior problems in 7-year-old twins: substantial genetic influence and negligible shared environmental influence for parent ratings and ratings by same and different teachers. Journal of Abnormal Child Psychology, 33(1), 113-130.

Schmitz, S., Cherny, S. S., \& Fulker, D. W. (1998). Increase in power through multivariate analyses. Behavior Genetics, 28(5), 357-363.

Shanahan, M. A., Pennington, B. F., Yerys, B. E., Scott, A., Boada, R., Willcutt, E. G., et al. (2006). Processing speed deficits in attention deficit/hyperactivity disorder and reading disability. Journal of Abnormal Child Psychology, 34(5), 585-602.

Shaywitz, S. E., \& Shaywitz, B. A. (2008). Paying attention to reading: the neurobiology of reading and dyslexia. Development and Psychopathology, 20(4), 1329-1349.

Shaywitz, S. E., Escobar, M. D., Shaywitz, B. A., Fletcher, J. M., \& Makuch, R. (1992). Evidence that dyslexia may represent the lower tail of a normal distribution of reading ability. The New England Journal of Medicine, 326(3), 145-150. 
Stage, S. A., Abbott, R. D., Jenkins, J. R., \& Berninger, V. W. (2003). Predicting response to early reading intervention from verbal IQ, reading-related language abilities, attention ratings, and verbal IQ-word reading discrepancy: failure to validate discrepancy method. Journal of Learning Disabilities, 36(1), 24-33.

Stuebing, K. K., Fletcher, J. M., LeDoux, J. M., Lyon, G. R., Shaywitz, S. E., \& Shaywitz, B. A. (2002). Validity of IQ-discrepancy classifications of reading disabilities: a meta-analysis. American Educational Research Journal, 39(2), 469-518.

Sumner, C. R., Gathercole, S., Greenbaum, M., Rubin, R., Williams, D., Hollandbeck, M., et al. (2009). Atomoxetine for the treatment of Attention-Deficit/Hyperactivity Disorder (ADHD) in children with ADHD and dyslexia. Child Adolesc Psychiatry Ment Health, 3, 40.

Thapar, A., Harrington, R., Ross, K., \& McGuffin, P. (2000). Does the definition of ADHD affect heritability? Journal of the American Academy of Child and Adolescent Psychiatry, 39(12), 15281536.

Tiu, R. D., Thompson, L. A., \& Lewis, B. A. (2003). The role of IQ in a component model of reading. Journal of Learning Disabilities, $36(5), 424-436$

Torgesen, J. K., Wagner, R. K., \& Rashotte, C. A. (1999). Test of Word Reading Efficiency (TOWRE). Austin: Pro-ed.

Trouton, A., Spinath, F. M., \& Plomin, R. (2002). Twins early development study (TEDS): a multivariate, longitudinal genetic investigation of language, cognition and behavior problems in childhood. Twin Research, 5(5), 444-448.

Trzesniewski, K. H., Moffitt, T. E., Caspi, A., Taylor, A., \& Maughan, B. (2006). Revisiting the association between reading achievement and antisocial behavior: new evidence of an environmental explanation from a twin study. Child Development, 77(1), 72-88.

Vellutino, F. R., Scanlon, D. M., \& Lyon, G. R. (2000). Differentiating between difficult-to-remediate and readily remediated poor readers: more evidence against the IQ-achievement discrepancy definition of reading disability. Journal of Learning Disabilities, 33(3), 223-238.

Vellutino, F. R., Fletcher, J. M., Snowling, M. J., \& Scanlon, D. M. (2004). Specific reading disability (dyslexia): what have we learned in the past four decades? Journal of Child Psychology and Psychiatry, 45(1), 2-40.

Vidyasagar, T. R., \& Pammer, K. (2010). Dyslexia: a deficit in visuospatial attention, not in phonological processing. Trends in Cognitive Sciences, 14(2), 57-63.

Wadsworth, S. J., Olson, R. K., Pennington, B. F., \& DeFries, J. C. (2000). Differential genetic etiology of reading disability as a function of IQ. Journal of Learning Disabilities, 33(2), 192-199.

Wagenmakers, E. J., \& Farrell, S. (2004). AIC model selection using Akaike weights. Psychonomic Bulletin \& Review, 11(1), 192-196.

Warner-Rogers, J., Taylor, A., Taylor, E., \& Sandberg, S. (2000). Inattentive behavior in childhood: epidemiology and implications for development. Journal of Learning Disabilities, 33(6), 520-536.

Wechsler, D. (1991). Wechsler Intelligence Scale for Children (3rd ed.). London: The Psychological Corporation.

Wigg, K. G., Feng, Y., Crosbie, J., Tannock, R., Kennedy, J. L., Ickowicz, A., et al. (2008). Association of ADHD and the
Protogenin gene in the chromosome $15 \mathrm{q} 21.3$ reading disabilities linkage region. Genes Brain and Behavior, 7(8), 877-886.

Willcutt, E. G., \& Pennington, B. F. (2000a). Comorbidity of reading disability and attention-deficit/hyperactivity disorder: differences by gender and subtype. Journal of Learning Disabilities, 33(2), 179-191.

Willcutt, E. G., \& Pennington, B. F. (2000b). Psychiatric comorbidity in children and adolescents with reading disability. Journal of Child Psychology and Psychiatry, 41(8), 1039-1048.

Willcutt, E. G., Pennington, B. F., \& DeFries, J. C. (2000). Twin study of the etiology of comorbidity between reading disability and attention-deficit/hyperactivity disorder. American Journal of Medical Genetics, 96(3), 293-301.

Willcutt, E. G., Pennington, B. F., Boada, R., Ogline, J. S., Tunick, R. A., Chhabildas, N. A., et al. (2001). A comparison of the cognitive deficits in reading disability and attention-deficit/ hyperactivity disorder. Journal of Abnormal Psychology, 110(1), $157-172$.

Willcutt, E. G., Pennington, B. F., Smith, S. D., Cardon, L. R., Gayan, J., Knopik, V. S., et al. (2002). Quantitative trait locus for reading disability on chromosome $6 \mathrm{p}$ is pleiotropic for attention-deficit/ hyperactivity disorder. American Journal of Medical Genetics, 114(3), 260-268.

Willcutt, E. G., Pennington, B. F., Olson, R. K., Chhabildas, N., \& Hulslander, J. (2005). Neuropsychological analyses of comorbidity between reading disability and attention deficit hyperactivity disorder: in search of the common deficit. Developmental Neuropsychology, 27(1), 35-78.

Willcutt, E. G., Betjemann, R. S., Wadsworth, S. J., Samuelsson, S., Corley, R., DeFries, J. C., et al. (2007a). Preschool twin study of the relation between attention-deficit/hyperactivity disorder and prereading skills. Reading and Writing, 20(1-2), 103-125.

Willcutt, E. G., Pennington, B. F., Olson, R. K., \& DeFries, J. C. (2007b). Understanding comorbidity: a twin study of reading disability and attention-deficit/hyperactivity disorder. American Journal of Medical Genetics. Part B: Neuropsychiatric Genetics, 144B(6), 709-714.

Willcutt, E. G., Betjemann, R. S., McGrath, L. M., Chhabildas, N., Olson, R., DeFries, J. C., et al. (2010a). Etiology and neuropsychology of comorbidity between RD and ADHD: the case for multiple deficit models. (Under review).

Willcutt, E. G., Boada, R., Riddle, M., Chhabildas, N., DeFries, J. C., \& Pennington, B. (2010b). Colorado Learning Difficulties Questionnaire: Validation of a parent-report screening measure. (Under review).

Williams, R. L. (2000). A note on robust variance estimation for cluster-correlated data. Biometrics, 56, 645-646.

Wood, A. C., Asherson, P., van der Meere, J. J., \& Kuntsi, J. (2009). Separation of genetic influences on attention deficit hyperactivity disorder symptoms and reaction time performance from those on IQ. Psychological Medicine, Published online 15 September 2009, DOI: 2010.1017/S003329170999119X.

Zumberge, A., Baker, L. A., \& Manis, F. R. (2007). Focus on words: a twin study of reading and inattention. Behavior Genetics, 37(2), 284-293. 